\title{
DEEP STRUCTURE OF THE SIBERIAN PLATFORM - CENTRAL ASIAN MOBILE BELT TRANSITION ZONE FROM TELESEISMIC DATA
}

\author{
V. V. Mordvinova1, M. M. Kobelev ${ }^{1,2}$, A. V. Treussov ${ }^{3}$, M. A. Khritova ${ }^{1,2}$, \\ D. S. Trynkova ${ }^{1}$, E. A. Kobeleva ${ }^{1,2}$, O. F. Lukhneva ${ }^{1}$ \\ ${ }^{1}$ Institute of the Earth's Crust, Siberian Branch of RAS, Irkutsk, Russia \\ ${ }^{2}$ Baikal Division of Geophysical Survey, Siberian Branch of RAS, Irkutsk, Russia \\ ${ }^{3}$ O.Yu. Schmidt Institute of Physics of the Earth of RAS, Moscow, Russia
}

\begin{abstract}
Deep velocity sections of the transition zone from the Siberian platform to the Central Asian mobile belt are constructed by teleseismic tomography and $P$-receiver function techniques. An array of the dense ancient Siberian craton is identified in the velocity sections with areas of high seismic velocity. In the SSW section MOBAL_2003, the surface boundary of the craton corresponds to the southern margin of the Siberian platform and is nearly vertical to a depth of $120 \mathrm{~km}$. At larger depths, the craton slides almost horizontally underneath the Tunka rift area. At depths from 150 to $250 \mathrm{~km}$, it is in contact with the area under the Khamar-Daban mountain range. In the southeast, according to the SE velocity section PASSCAL_1992 across the South Baikal basin and the Khamar-Daban mountain range, the Siberian craton thickness is reduced from 270 to $150 \mathrm{~km}$ at the contact of the Siberian platform with the Baikal folded area. In this contact zone, the upper part of the craton is wedge-shaped and has an angle of about $45^{\circ}$ with the ground surface; it completely tapers off at a depth of $150 \mathrm{~km}$ to the east of Lake Baikal. The vertical configuration of the southern segment of the Siberian craton, which evolved with time, may determine the nature of the Baikal rifting in the Cenozoic.
\end{abstract}

Key words: tomography; $P$-receiver function; seismic velocity sections; Siberian platform; Central Asian mobile belt; Baikal rifting in the Cenozoic

Recommended by E.V. Sklyarov

For citation: Mordvinova V.V., Kobelev M.M., Treussov A.V., Khritova M.A., Trynkova D.S., Kobeleva E.A., Lukhneva O.F. 2016. Deep structure of the Siberian platform - Central Asian mobile belt transition zone from teleseismic data. Geodynamics \& Tectonophysics 7 (1), 85-103. doi:10.5800/GT-2016-7-1-0198.

Для цитирования: Мордвинова В.В., Кобелев М.М., Треусов А.В., Хритова М.А., Трынкова Д.С., Кобелева Е.А., Лухнева О.Ф. Глубинное строение переходной зоны Сибирская платформа - ЦентральноАзиатский подвижный пояс по телесейсмическим данным // Геодинамика и тектонофизика. 2016. T. 7. № 1. C. 85-103. doi:10.5800/GT-2016-7-1-0198.

\section{ГЛУБИННОЕ СТРОЕНИЕ ПЕРЕХОДНОЙ ЗОНЫ СИБИРСКАЯ ПЛАТФОРМА - ЦЕНТРАЛЬНО-АЗИАТСКИЙ ПОДВИЖНЫЙ ПОЯС ПО ТЕЛЕСЕЙСМИЧЕСКИМ ДАННЫМ}

\author{
В. В. Мордвинова ${ }^{1}$, М. М. Кобелев ${ }^{1,2}$, А. В. Треусов ${ }^{3}$, М. А. Хритова ${ }^{1,2}$, \\ Д. С. Трынкова ${ }^{1}$, Е. А. Кобелева ${ }^{1,2}$, О. Ф. Лухнева ${ }^{1}$ \\ ${ }^{1}$ Институт земной коры СО РАН, Иркутск, Россия \\ ${ }^{2}$ Байкальский филиал Геофизической службы СО РАН, Иркутск, Россия \\ ${ }^{3}$ Институт физики Земли им. О.Ю. Шмидта РАН, Москва, Россия
}




\begin{abstract}
Аннотация: По скоростным разрезам, построенным методами телесейсмической томографии и продольной приемной функции, найдены особенности вертикальной конфигурации юга Сибирского кратона, влияющие на Байкальский рифтогенез. Кратон ассоциируется с выявленными на моделях областями повышенной сейсмической скорости. На юго-юго-западном разрезе MOBAL_2003 граница кратона на поверхности соответствует южной окраине Сибирской платформы и до глубины 120 км близка к вертикали. Глубже кратон почти горизонтально уходит под Тункинский рифт, достигая подножия Хамар-Дабана в интервале глубин 150-250 км. На юго-востоке вертикальная конфигурация границы кратона выявляется по форме высокоскоростной аномалии разреза PASSCAL_1992, пересекающего Южнобайкальскую впадину и Хамар-Дабан. Мощность аномалии, свидетельствующей о более высокоскоростной и плотной среде, на контакте Сибирской платформы с Байкальской складчатой областью уменьшается от 270 до 150 км. В районе контакта высокоскоростная аномалия принимает форму клина, который под углом около $45^{\circ}$ задвигается от дневной поверхности под озеро Байкал и на глубине 150 км выклинивается восточнее озера.
\end{abstract}

Ключевые слова: томография; продольные приемные функции; сейсмические скоростные разрезы; Сибирская платформа; Центрально-Азиатский подвижный пояс; кайнозойский Байкальский рифтогенез

\section{1. ВВЕДЕНИЕ}

Как единая консолидированная структура Сибирский кратон окончательно был сформирован к концу раннего протерозоя, когда стал составной частью суперконтинента Пангея- 1 . Большинство его южных границ образовалось в неопротерозое в связи с распадом суперконтинента Родиния [Sklyarov, 2006]. В современной структуре юг кратона обрамлен разновозрастными складчато-надвиговыми поясами: Енисейским, Саяно-Байкальским, Монголо-Охотским. Эта намеченная на основании палеотектонических реконструкций граница считается довольно условной, поскольку первичные контуры кратона неизвестны и не установлены истинные амплитуды горизонтальных перемещений по ограничивающим разрывным зонам. Между тем именно знание более точной конфигурации вертикальных границ Сибирского кратона позволит более обоснованно судить о роли и перспективах его взаимодействия со смежными тектоническими областями.

Результаты геофизических исследований [Zorin et al., 2002], выполненных по Юго-Западному Прибайкалью, позволили предположить, что фундамент кратона прослеживается далеко под горное сооружение Хамар-Дабан, то есть под складчатую систему [Sklyarov, 2006]. Подобное явление установлено для многих кратонов, однако уточнение глубинной границы Сибирского кратона в переходной зоне к Центрально-Азиатскому подвижному поясу обычно затруднено недостатком сейсмологических наблюдений, необходимых для одновременного исследования строения земной коры и верхней мантии региона.

В изучении скоростного строения Сибирского кратона принимали участие многие коллективы, используя различные системы наблюдения. Первый и важный вклад в представление о скоростной структуре земной коры и верхней мантии на юге кратона сделан основательными работами по глубинному сейсмическому зондированию (ГСЗ) по данным химических взрывов. В результате установлены средние скорости продольных и поперечных волн в коре $\left(V_{P}=6.4 \mathrm{kм} / \mathrm{c}, V_{S}=3.7 \mathrm{\kappa m} / \mathrm{c}\right)$, практически не изменяющиеся в пределах Байкальской рифтовой зоны (БРЗ) и окраины Сибирской платформы и принимаемые теперь, при исследованиях другими методами, за опорные. Значения скорости под корой платформы: $V_{P}=8.1-8.2$ км $/ \mathrm{c}, V_{S}=4.6$ км/с. В то же время выявлена существенная неоднородность скоростного строения как по вертикали, так и по горизонтали: изменение толщины коры под южной частью Сибирской платформы от 37 до 45 км, а в пределах БР3 - от 34 до 55 км (минимальные значения отмечены под центральной частью Байкальской впадины, максимальные - на юго-западном фланге рифтовой зоны). Главные особенности скоростной структуры земной коры и верхов мантии, отличающие зону рифта от не испытавшей интенсивной тектонической активизации Сибирской платформы: отсутствие четких протяженных границ, наличие под большинством рифтовых впадин низкоскоростного слоя на глубинах около 12-17 км с понижением скорости продольных волн относительно вмещающей среды на 0.3 км/с, зона аномально низкой скорости в самой верхней мантии под оз. Байкал $(V p=7.5-7.9$ км/с, $V s=4.3 \pm 0.1 \mathrm{\kappa m} / \mathrm{c}$ ] [Puzyrev, 1981, 1993; Suvorov et al., 2002]. Центральная часть низкоскоростной верхнемантийной зоны соответствует минимальной мощности коры под Байкальской впадиной и представ- 
ляется в виде утолщенного под рифтом гриба с почти вертикальным ограничением со стороны Сибирской платформы и плавным выклиниванием в юго-восточном направлении [Puzyrev et al., 1974]. Однако в таком представлении области аномальной мантии не было большой уверенности ввиду малой детальности исследований. На участках, где проводились более детальные исследования, в зонах пониженных скоростей исследованиями ГСЗ выявлены включения с «нормальной» скоростью, а в обрамляющем аномальную область поле «нормальных» скоростей найдены включения пониженных скоростей. Было высказано предположение, что перечисленные скоростные особенности обусловлены неотектонической активизацией [Puzyrev, 1981].

Результаты исследования скоростной структуры Центральной Байкальской впадины [ten Brink, Taylor, 2002], выполненные по данным наблюдений океаническими донными сейсмометрами [Scholz et al., 1993], по-видимому, также свидетельствуют о неоднородности поля скоростей. Тен Бринк и Тэйлор определили, что мощность земной коры вдоль Центральной впадины на 70-километровом участке восточнее острова Ольхон равна 39.0-42.5 км; нижний слой коры толщиной 8 км является высокоскоростным (7.05-7.40 км/с) при нормальной мантийной скорости (8 км/c). Высокоскоростная нижняя кора под Центральной Байкальской впадиной проинтерпретирована как часть Сибирской платформы, которая не была значительно утонена или изменена в ходе рифтинга.

По уникальным записям мирных ядерных взрывов вдоль нескольких крупномасштабных профилей на Сибирском кратоне скоростная структура прозондирована методом ГСЗ до больших глубин в мантии. Два профиля, «Метеорит» и «Рифт», с северо-запада на юго-восток параллельно друг другу проходят через Сибирский кратон и пересекают оз. Байкал в его южной и северной части. Наиболее известна первая модель ГСЗ по профилю «Рифт» [Egorkin et al., 1996]. Стремясь к простоте в разработке начального приближения и соответствию результатов наблюденным годографам продольных волн от границ в коре и верхней мантии, интерпретаторы получили довольно сложную слоистоблоковую модель до глубины 120 км. Модель «Рифт», рассчитанная до глубины 300 км [Pavlenkova et al., 2002], многое сохранила от скоростного разреза 1996 года. В модели «Рифт» до глубины 410 км [Suvorov et al., 2010] не детализируется кора, но выявляется ряд высокоскоростных и низкоскоростных блоков в интервале глубин 40-200 км, которые корреспондируются с геоморфологией. К сожалению, близость Байкала к юго-восточному концу линии взрывов не позволила по профилю «Рифт» прозон- дировать мантийную структуру под озером детальнее и глубже 70 км. Независимо друг от друга построены два скоростных разреза по профилю «Метеорит» [Pavlenkova, 2012; Suvorov et al., 2013]. Эти наиболее новые модели, как и разрезы по профилю «Рифт» [Pavlenkova et al., 2002; Suvorov et al., 2010], сильно различаются между собой в принципиальных деталях (по количеству и конфигурации крупных блоков литосферы, по скорости в этих блоках, по наличию или отсутствию астеносферы). Неоднозначность в скоростных моделях инициирует продолжение глубинных исследований.

В настоящее время все большее развитие получают методы изучения строения Земли по естественным источникам возбуждения сейсмических волн (используются поверхностные и объемные волны, генерируемые далекими землетрясениями на неоднородностях структуры в районах регистрации этих волн). В данной работе анализируются предшествующие и новые результаты, полученные различными методами по телесейсмическим данным вдоль профилей через южную и юговосточную окраину Сибирского кратона. Анализ построенных независимо друг от друга скоростных моделей направлен на получение более определенного представления о глубинной структуре. Главное внимание уделено вертикальной конфигурации окраин Сибирского кратона, во многом влияющей на формирование и состояние СаяноБайкальского региона.

\section{2. ТЕЛЕСЕЙСМИЧЕСКИЕ МЕТОДЫ ИССЛЕДОВАНИЯ ГлУБИННОЙ СТРУкТУРЫ}

Модели, рассмотренные в статье, выполнены хорошо зарекомендовавшими себя методами, подробно представленными в специальной литературе. Отметим лишь те особенности методологии, которые использованы при построении скоростных моделей и оценке их детальности.

\section{1. ПОВЕРХНОСТНО-ВОЛНОВАЯ ТОМОГРАФИЯ}

При существующей неравномерной сети сейсмостанций наиболее общее представление о распределении скоростей сейсмических волн на земном шаре до глубины 700 км получено методом поверхностно-волновой томографии [Ritzwoller, Levshin, 1998; Yanovskaya, Kozhevnikov, 2003]. Эффективность и популярность метода обусловлены отсутствием необходимости для получения исходных данных иметь систему наблюдения с плотным расположением сейсмостанций, а также отсутствием необходимости записей одного и того же сейсмического события многими станциями (что, напротив, 
требуется для кинематического метода томографии по объемным волнам). Поверхностно-волновая томография, использующая длинноволновые записи далеких землетрясений, не дает разрешения в коре и предназначена для исследования верхней мантии при заданной осредненной модели коры. Для восстановления трехмерной скоростной структуры мантии в качестве исходных данных используются дисперсионные кривые групповых и фазовых скоростей поверхностных волн, полученные на участках между парами регистрирующих станций. Результат обычно представляют карты, начиная от глубины 50 км, с шагом по глубине 50 км, и двумерные скоростные разрезы, пересекающие основные тектонические структуры. При использовании опорной сети широкополосных станций IRIS, удаленных друг от друга в среднем на 500 км, и записей сильных землетрясений от очагов, удаленных на 7000-15000 км, глубина исследований среды близка к 600-650 км. Разрешение моделей по вертикали 30-50 км, а по горизонтали 300-500 км.

\section{2. ТЕЛЕСЕЙСМИЧЕСКАЯ ТОМОГРАФИЯ ПО ОБЪЕМНЫМ ВОЛНАМ}

Наличие достаточно плотных сетей позволяет достичь лучшего латерального разрешения классическим методом телесейсмической томографии по невязкам времен пробега объемных волн от землетрясений, удаленных более чем на 2000 км, что обеспечивает малые наклоны сейсмических лучей в точке приема [Aki et al., 1977]. Инверсией невязок определяются отклонения региональной скоростной структуры от стандартной сейсмической модели Земли. В данном исследовании все расчеты выполнены относительно стандартной модели IASPEI91 [Kennett, 1991], введенной в используемый для анализа трехкомпонентных сейсмограмм программный пакет SeismicHandler [Stammler, 1993].

Для хорошего соотношения сигнал/шум используются волны, приходящие первыми в пункт наблюдения (P, РКР). Например, при изучении скоростной структуры вдоль международного профиля PASSCAL_1992 выполнен двумерный вариант томографической инверсии невязок времени пробега телесейсмических объемных волн $P$ и $P K P$ [Mordvinova et al., 2000]. Томография вдоль профиля MOBAL_2003 выполнена инверсией невязок Р-волн [Mordvinova et al., 2015].

Необходимым условием для получения достоверных моделей является соответствие системы наблюдений и подходов к анализу и инверсии данных наблюдений. С помощью линейной группы станций может быть получен только двумерный (глубина-расстояние) скоростной разрез вдоль профиля при условии, что эпицентры землетрясе- ний находятся в створе с профилем в двух противоположных азимутах.

Из времени пробега волны вычитается время для стандартной модели Земли. В определенные таким образом невязки времени пробега вводятся поправки на эллиптичность Земли и вариации высоты местности. Затем невязки центрируются вычитанием их среднего значения на профиле, т.е. важны и анализируются не сами невязки, а их колебания вокруг некоторого уровня на станциях профиля (центрированные невязки). Такой подход успешно исключает ошибки в определении времени возникновения землетрясения и глубины гипоцентра, влияние особенностей скоростной структуры в районе очага землетрясений, находящегося далеко за пределами области наблюдений, а также влияние пути от землетрясения до профильной системы наблюдения.

С учетом малости возмущений скорости невязка представляется как интеграл возмущения медленности (т.е. величины, обратной к скорости), взятый вдоль невозмущенного луча. Изучаемая среда разбивается на систему прямоугольников с постоянным значением скорости. Задача сводится к оценке возмущений медленности в каждом прямоугольнике путем решения соответствующей системы алгебраических линейных уравнений.

Важным методическим моментом является параметризация моделируемого скоростного разреза. Необходимо (1) задать глубину разреза, то есть мощность того неоднородного слоя, в котором формируются невязки времен пробега, и (2) разделить плоскость разреза на прямоугольные блоки. Выбор глубины разреза достаточно субъективен, однако при использовании записей телесейсмических событий с их субвертикальными в районе регистрации сейсмическими лучами не следует задавать глубину, превышающую половину длины сейсмического профиля. В противном случае нижняя часть скоростного профиля может оказаться недостаточно контролируемой пересечением встречных сейсмических лучей, что ведет к растягиванию скоростных аномалий по вертикали. Для получения хорошо определяемой системы алгебраических линейных уравнений размер блоков выбирается в зависимости от расстояния между станциями и количества используемых землетрясений. Поскольку расстояния между сейсмическими лучами с глубиной увеличиваются, размер блоков также увеличивается. Качество системы наблюдения проверяется численным тестированием [Mordvinova et al., 2000]. В конечном итоге результатом интерпретации флуктуации невязок является распределение флуктуаций сейсмической скорости вокруг ее среднего значения для Земли в соответствующем интервале глубин (задаваемое обычно в процентах). Затем 
применяется техника сглаживания. Иногда сглаживание не используется [Burkholder et al., 1995; Tiberi et al., 2003].

На основе данной методики в двумерном ее варианте А.В. Треусовым по разработанной им программе рассчитаны Р-томографические модели вдоль профилей PASSCAL_1992 и MOBAL_2003 [Mordvinova et al., 2000, 2015]. Характеристики качества полученных в результате моделей довольно близки и вполне удовлетворительны для данного класса задач. Томографические модели объясняют 56 \% исходных невязок, стандартное отклонение скоростных вариаций равно $1.7 \%$, значения диагональных элементов матрицы разрешения превышают 0.5 .

\section{3. МЕТОД ПРОДОЛЬНОЙ ПРИЕМНОЙ ФУНКЦИИ}

Этот метод развит в ряде работ [Vinnik, 1977; Ammon et al., 1990; Kosarev et al., 1993] и применяется для исследования глубинного строения в различных регионах в основном по записям широкополосных станций [Kind et al., 1995; Gao et al., 2004; Mordvinova et al., 2007].

Использующий частотный диапазон записей 0.01-0.90 Гц и близвертикальные сейсмические лучи далеких землетрясений метод продольных приемных функций по своей детальности является средним звеном между глубинным сейсмическим зондированием и региональной томографией. Он хорошо зарекомендовал себя при профильных наблюдениях и при равномерно расположенных по площади сейсмостанциях [Mordvinova, Artemyev,
2010]. Метод успешно применяется и на отдельно взятой станции, чем выгодно отличается от сейсмической томографии, поскольку по мере расширения сети сейсмостанций двумерные и трехмерные модели, создаваемые на базе одномерных моделей $V_{S}(h)$, могут быть перестроены с учетом новых данных. Разрешение скоростных разрезов в таком случае повышается, и, тем самым, уточняется информация о глубинном строении.

Задача инверсии продольных приемных функций состоит в расчете изотропных горизонтальнослоистых моделей подстанционной скоростной структуры на основании подбора теоретических приемных функций к наблюдаемым, обусловленным вступлениями в коде $P$-волны обменных поперечных волн, генерируемых на границах скоростных неоднородностей среды в окрестности регистрирующей станции. Латеральная неоднородность среды может быть представлена по данным ряда станций в виде мозаики отдельных однородных блоков.

Для получения сведений о сейсмических скоростях в коре и в верхах мантии на южной окраине Сибирского кратона по записям объемных волн телесейсмических событий применена модификация метода, выполненная Л.П. Винником [Vinnik, 1977].

(1) Согласно данной модификации, для выделения вторичных поперечных волн компоненты $f_{z}(t)$, $f_{N}(t)$ и $f_{E}(t)$ исходной сейсмограммы проецируются на оси координатной системы, связанной с направлениями, для которых смещения в продольной и обменной волнах максимальны. Для $P$-волны это направление (ось $L$, рис. 1, б) наиболее точно опре-



Рис. 1. Моделирование волновой трассы $S V$ методом свертки $\left(^{*}\right)$ импульсного набора коэффициентов обмена $r(t)$ волны $P S$ с волной $P$, приходящей из полупространства на нижнюю границу слоистой среды под станцией [Bertrand, Deschamps, 2000] (a) и поляризация волн $P$ и $S V$ в плоскости $Z, R($ б).

Fig. 1. $S V$ waveforms simulation by the convolution $\left({ }^{*}\right)$ of the impulse set of converted ratios $r(t)$ of $P S$ wave with $P$ wave coming from the semi-space to the lower border of the layered medium under the station [Bertrand, Deschamps, 2000] (a) and polarization of $P$ and $S$ waves in $Z, R$ plane (б). 
деляется анализом вертикально-радиальной ковариационной матрицы, построенной по первым периодам колебаний записанного станцией землетрясения. Горизонтальная $R(t)$ компонента смещения вычисляется по формуле, использующей теоретический обратный азимут $A z_{T}$ со станции на эпицентр:

$$
R(t)=f_{N}(t) \cos A z_{T}+f_{E}(t) \sin A z_{T} .
$$

Если $e$ - угол между главным направлением в $P$ волне и горизонталью, то

$$
L(t)=f_{Z}(t) \sin e+R(t) \cos e .
$$

Максимальная амплитуда колебаний в $S V$-волне выделяется в направлении, перпендикулярном $L$ (ось $S V$ на рис. 1):

$$
S V(t)=R(t) \sin e-f_{Z}(t) \cos e .
$$

Такой подход для выделения обменных волн $S V$ (фазы $P s, P p P m s$ и т.п.) является более надежным и точным, чем обычно применяемый упрощенный подход, ограничивающийся анализом горизонтальной компоненты (например [Ammon et al., 1990; Gao et al., 2004]).

(2) Далее производится обратная фильтрация (деконволюция) - процедура, противоположная свертке (рис. $1, a$ ), исключающая эффекты очага, особенности строения Земли вне структуры под станцией и влияние приборов. Деконволюция выполняется во временной области [Berkhout, 1977]. Для создания обратного фильтра используется форма $P$-волны на $L$-компоненте, так как предполагается, что форма волны в однородной мантии близка к форме волны на поверхности. Деконволюция трансформирует форму $P$-волны каждого события в стандартный сигнал (рис. $1, a$ ). Вторичные фазы, подобные $P S$, после деконволюции также стандартизованы и нормализованы на величину максимума $L$-компоненты.

(3) Стандартизованные компоненты записей землетрясений каждой станции суммируются в узких диапазонах азимутов (10-30 $)$ для подавления шума и выделения регулярных особенностей. Форма стандартизованной L-компоненты стремится к дельта-функции, максимум которой соответствует вступлению Р-волны на станцию. У $S V$-функций в интервале 4-6 секунд после вступления $P$-волны на станцию, как правило, отмечается максимум повышенной интенсивности, который соответствует запаздыванию $\Delta t$ относительно волны $P$ обменной $P S$-волны, образованной на подошве земной коры самой резкой границе на пути распространения волн. Зная среднюю скорость Р-волн, отношение скоростей $k=V_{\mathrm{P}} / V_{\mathrm{S}}$ и пренебрегая различием в углах падения сейсмических лучей $P$ и $S\left(i_{P} \cong i_{S} \cong i\right)$, по запаздыванию $(\Delta t)$ максимума PS-волны относительно $P$-волны можно приблизительно оценить толщину коры $H$ :

$$
H=\frac{\Delta t \cdot V_{P} \cdot \cos i}{k-1}
$$

Оценки толщины коры могут служить в качестве первых приближений для процедуры инверсии (восстановление скоростного разреза сейсмических волн $V_{S}(h)$ по полученным в районе наблюдения приемным функциям). Программа инверсии разработана Г.Л. Косаревым [Kosarev et al., 1993]. За первое приближение в итерационной процедуре инверсии принимается обычно скоростная модель, соответствующая известным осредненным данным о скоростях в исследуемом регионе. В наших расчетах в качестве первого приближения для земной коры принята усредненная модель для СаяноБайкальской области, но без слоев пониженной скорости [Puzyrev, 1993], для подкоровой мантии принята скорость продольных волн 8 км/с, соотношение скоростей $V_{P} / V_{S}=1.73$ в коре и 1.8 - в мантии.

Среднеквадратичная погрешность определения скорости поперечных волн в интервале глубин 0-80 км оценивается в среднем величиной \pm 0.1 км/с, причем с увеличением глубины погрешность уменьшается.

Для построения скоростных разрезов вдоль профилей станций (двумерных моделей) применен стандартный метод линейной интерполяции и триангуляции. Вертикальное разрешение разрезов, согласно одномерным моделям $V_{S}(h)$ и с учетом процедуры сглаживания, составляет 0.5-2.0 км в коре и 3-5 км в мантии. Разрешение по горизонтали определяется расстоянием между сейсмостанциями. Топография региона исследования сложная (рис. 2), а станции в основном расположены на равнинных участках, но благодаря сейсмическому сносу (угол падения используемых сейсмических лучей примерно $25^{\circ}$ ) скоростные разрезы дают информацию и о глубинах под горными районами.

\section{3. МЕРИДИОНАЛЬНЫЙ РАЗРЕЗ БРАТСКОЕ ВОДОХРАНИЛИЩЕ - ЗАКАМЕНСК ПО ПРОДОЛЬНЫМ ПРИЕМНЫМ ФУНКЦИЯМ}

Анализ сейсмической анизотропии по фазам SKS в Сибири и Монголии [Gao et al., 1994; Barruol et al., 2008] показал целесообразность исследования детальной скоростной структуры в различных направлениях от наблюдающих станций для получе- 


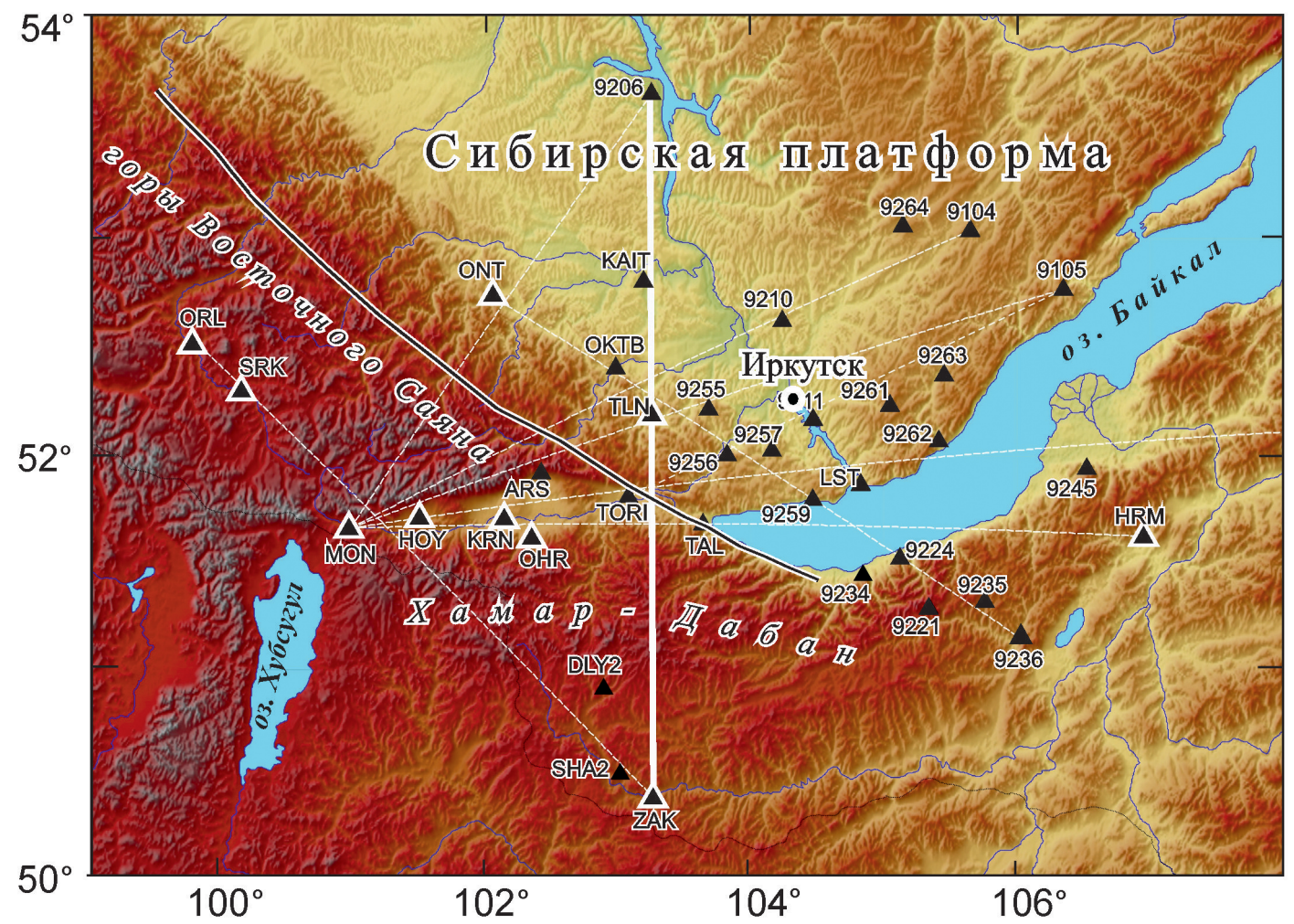

Рис. 2. Карта рельефа исследуемого региона.

Черно-белая линия - Главный Саянский разлом. Треугольниками с соответствующей кодировкой обозначены сейсмические станции. Черно-белые треугольники - действующие широкополосные станции. Толстая белая линия - направление меридионального скоростного разреза 9206-ZAK.

Fig. 2. Topography map of the study area.

The black-and-white line - Main Sayan Fault. Seismic stations are marked by triangles with the appropriate codes. The black and white triangles are existing broadband stations. The thick white line shows the direction of the meridional velocity section 9206-ZAK.

ния более объективной характеристики среды. С этой целью с 2009 г. ведутся постоянные наблюдения группой из девяти широкополосных сейсмостанций системы Guralp, установленных по обе стороны Главного Саянского разлома (рис. 2) - в ключевой в тектоническом отношении зоне сочленения докембрийского Сибирского кратона с Центрально-Азиатским подвижным поясом.

Из накопленных за годы непрерывной регистрации записей далеких землетрясений выделены продольные приемные функции ( $P$-receiver function, или $P R F$ ) для различных диапазонов азимутов относительно каждого пункта наблюдения. Границы азимутальных диапазонов с потенциально разнородной скоростной структурой определены по изменению форм PRF. Полученные для этих диапазонов одномерные модели, как и более ранние модели [Mordvinova et al., 2007; Mordvinova, Artemyev, 2010], вошли в скоростные разрезы вдоль профилей разных направлений (рис. 2). Меридиональный скоростной разрез по профилю 9206-ZAK характеризирует переходную область от относительно стабильной Сибирской платформы к ЦентральноАзиатскому подвижному поясу (рис. 3).

На рисунке $3, a$, показаны приемные функции $P R F$, выделенные из записей южных и юго-восточных землетрясений. Волновые трассы $P R F$ размещены на рисунке $3, a$, с учетом расстояния между станциями профиля. Красными кружками отмечены фазы, соответствующие коромантийному переходу. На рис. 3, б, красными линиями выделены графики восстановленных скоростных разрезов. Черные графики - первые приближения, разработанные, как отмечено в разделе 2.3 , на основании исследований ГСЗ в Саяно-Байкальской складчатой области с учетом позиций коромантийных фаз на продольных приемных функциях (рис. $3, a$ ).

Почти все рассчитанные модели (рис. 3 , б) имеют низкоскоростные слои (слабо или резко выраженные) и градиентные коромантийные переходы. Под Торской рифтовой впадиной (станция TORI) выделена наиболее нетипичная ослабленная коромантийная фаза (рис. $3, a$ ), которой в восстановленном скоростном разрезе (рис. 3 , б) соответствует 

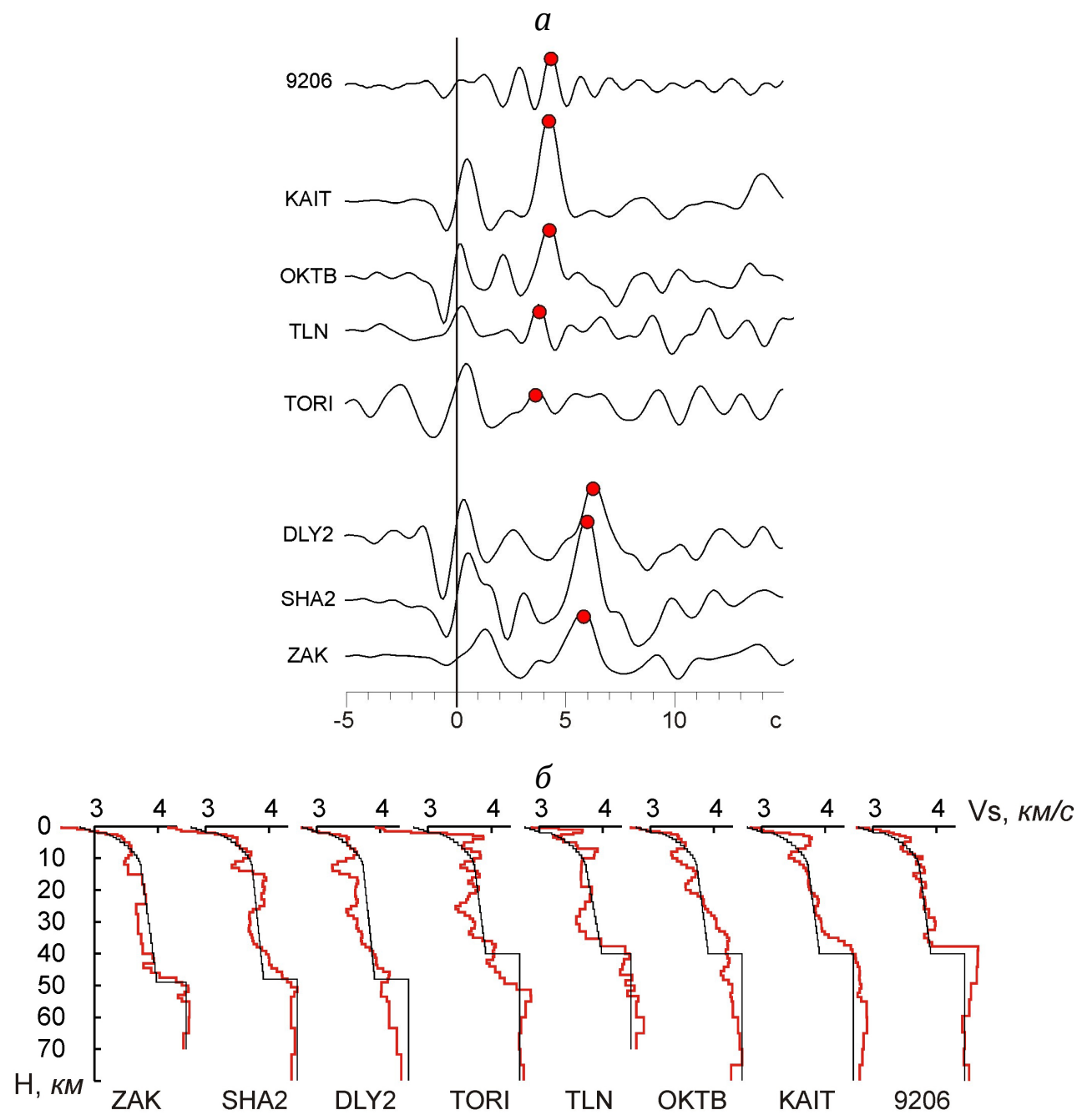

Рис. 3. $S V$-приемные функции в районах сейсмостанций $(a)$ и восстановленные по этим приемным функциям одномерные $S$-скоростные разрезы (б). Пояснения в тексте.

Fig. 3. $S V$-receiver functions in areas monitored by seismic stations $(a)$ and one-dimensional $S$-velocity sections defined according to these receiver functions (б). Explanations are in the text.

сложный переход от низкоскоростной коры на глубине 35 км к локальной области высокоскоростной мантии на глубине 50 км. Наиболее резкий коромантийный переход под северной платформенной станцией профиля (9206). Без связи с геоморфологией трудно объяснить причины разнообразия приемных функций и полученных по ним зависимостей скорости от глубины (рис. $3, a$, б).

Более наглядна двумерная модель - скоростной разрез 9206-ZAK, построенный по одномерным моделям с учетом расстояния между станциями (рис. 4). Разрез сопровождается топографией вдоль профиля, с помощью которой выявляется, что земной коре краевой зоны Сибирской платформы свойственно довольно равномерное увеличение скорости с глубиной за исключением слоя пониженной скорости в интервале глубин 6-12 км (предположительно мелонитизированная зона древнего надвига [Zorin et al., 2002]). В переходной к горной области зоне (территория Шарыжалгайского метаморфического комплекса [Sklyarov, 2006]) сохраняется тенденция нарастания скорости с глубиной, но по появляющимся низкоскоростным и высокоскоростным включениям можно предположить деформирование и переработку вещества коры, особенно ее верхней и нижней части. Под горной территорией чрезвычайно сложная структура коры с чередованием слоев и линз повышенной и пониженной скорости. Принято считать, что пониженные скорости в таких случаях свидетельствуют о гранулитовых ослабленных слоях, которые способствуют перемещению материала в тектонически активных зонах [Lobkovsky, 1988]. При переходе к горной области не только увеличивается толщина коры, пределом для которой нами принята изолиния 4.3 км/с, но также 


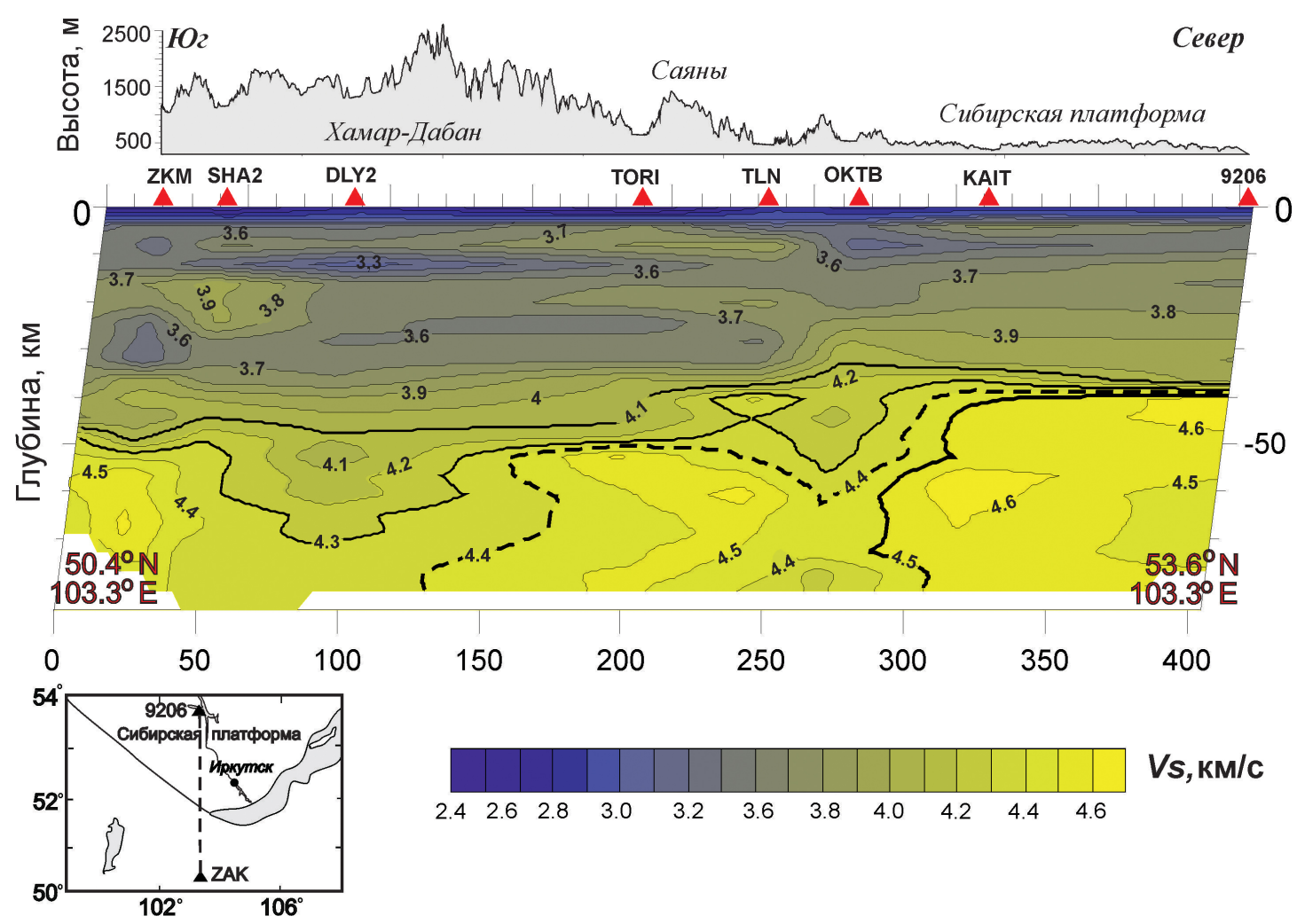

Рис. 4. $V_{S}$-разрез и топография вдоль профиля 9206-ZАК (Братское водохранилище - г. Закаменск).

Направление профиля показано пунктиром на врезке. Треугольниками отмечены позиции сейсмостанций (согласно рис. 2); изолинии скоростей от 2.4 до 4.6 км/с проведены с шагом 0.1 км/с. Другие пояснения в тексте.

Fig. 4. $V_{S}$-section and topography along profile 9206-ZAK (Bratsk reservoir - Zakamensk).

The direction of the profile is shown by dotted lines on the insert. The triangles mark the position of seismic stations (as shown in Fig. 2); velocity isolines from 2.4 to $4.6 \mathrm{~km} / \mathrm{s}$ are drawn with a step of $0.1 \mathrm{~km} / \mathrm{s}$. Other explanations are in the text.

полностью меняется характер коромантийного перехода. Как уже показала одномерная модель по станции 9206, в районе Сибирской платформы на глубине 38-39 км залегает наиболее контрастный раздел Мохо. Здесь скорость меняется скачком от 4.0 до 4.6 км/с, то есть вероятно, что земная кора, защищенная тем, что расположена на плотной, прочной мантийной литосфере кратона, по крайней мере, с позднего протерозоя не испытывала глубинных деформаций.

Выделенная жирной изолинией 4.5 км/с область мантийной литосферы, по-видимому, является наиболее неизмененной частью кратона в пределах данного разреза в отличие от деформированной его области южнее (ограничена пунктирной изолинией $4.4 \mathrm{~km} / \mathrm{c}$ ). Интервал между изолиниями 4.3 и 4.4 км/с затруднительно идентифицировать с низами коры или с деформированной кровлей окраины Сибирского кратона. Вполне оправдано появление в этом интервале ослабленной прослойки (возможно, коромантийной смеси), создающейся при пододвигании кратона под более низкоскоростную (низкоплотностную) и, тем самым, более плавучую и пластичную южную область коры и мантии. К сожалению, в отсутствие станций между Далахаем (DLY2) и Торами (TORI) интерполяция несколько искажает образ мантийной кровли кратона. Но, судя по горному рельефу южнее Саян и по сведениям об изостатической компенсации в Южной Сибири преимущественно на уровне подошвы коры [Zorin et al., 1988], можно предполагать, что это искажение невелико.

\section{4. ХАРАКТЕРИСТИКА ЮЖНОЙ ОКРАИНЫ СИБИРСКОГО КРАТОНА}

Как видим, только по модели коры и тонкого слоя подкоровой мантии трудно судить о такой крупной тектонической структуре, как кратон. Рассмотрим, кроме того, три томографических разреза (рис. 5) южной окраины Сибирского кратона до глубины 300,400 и 600 км.

Разрезы MOBAL А и Б, как упомянуто выше (раздел 2.2), выполнены инверсией центрированных невязок времен пробега Р-волн по одним и тем же 

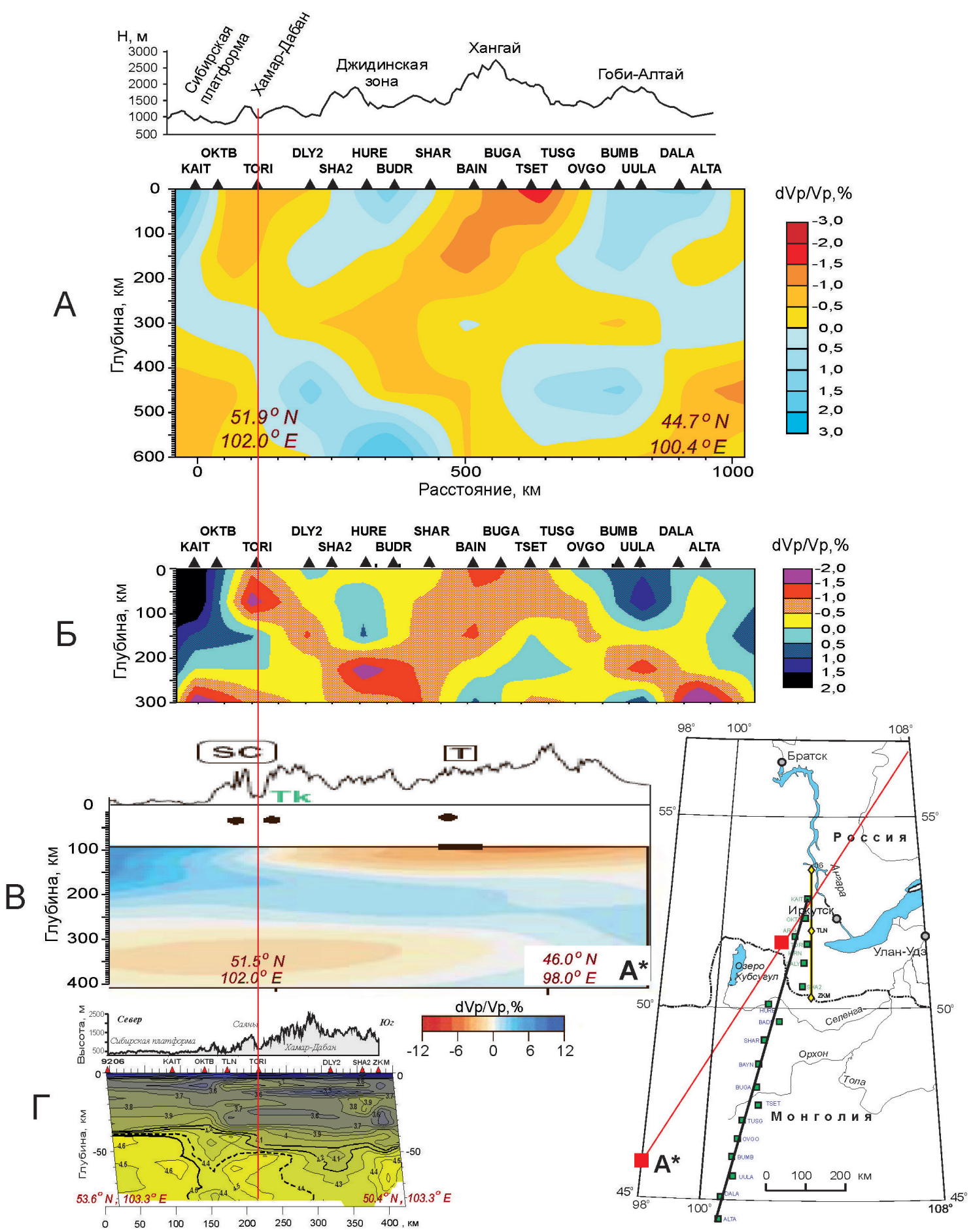

Рис. 5. Сопоставление (верификация) скоростных разрезов южной окраины Сибирского кратона и смежных тектонических областей.

А и Б - P-томография MOBAL_2003 (зеленые квадраты на карте - сейсмостанции MOBAL); В - поверхностно-волновой разрез [Emmerson et al., 2006] (разрез на карте нанесен красной линией, красные квадраты отмечают пересечение профилем Тункинского рифта и конец разреза А*); Г - меридиональный разрез по данным $P$-приемных функций (основное направление профиля - черная линия с желтыми ромбиками). Красная вертикаль в районе Тункинского рифта - ориентир для взаимосвязи всех моделей. Модели показаны в одном масштабе, только Г растянута по глубине.

Fig. 5. Comparison (verification) of high-speed profiles of the southern margin of the Siberian craton and the adjacent tectonic areas.

A and $\mathbf{6}$ - $P$-tomography MOBAL_2003 (in the map, green boxes show seismic MOBAL seismic stations); $\mathbf{B}$ - surface-wave profile [Emmerson et al., 2006] (in the map, the red line shows the profile route; red boxes mark the termination of profile $A^{*}$ and the point where the profile crosses the Tunka rift); $\boldsymbol{\Gamma}$ - meridional section from $P$-receiving functions (the main route of the profile is shown by the black line with yellow rhombs). The red vertical line near the Tunka rift is a correlation reference mark for all the models. The models are shown in the same scale, except the depth-stretched meridional section $(\boldsymbol{\Gamma})$. 
данным, но с применением различной параметризации. Глубина модели A [Mordvinova et al., 2015] вдвое больше глубины модели Б. Процедура инверсии, исходя из решения системы уравнений для отрезков встречных наборов сейсмических лучей, распределяет интенсивность невязок по площади. Соответствующие искомым невязкам на больших глубинах отрезки лучей удлиняются примерно пропорционально увеличению глубины. Выигрывая в глубинности, мы проигрываем в разрешении для более глубоких частей модели. Тем не менее к набору подобных аномалий, выявленных в А и Б до глубины 300 км, при большей глубинности А мы получили дополнительную информацию о том, что Тункинская (TORI) и Хангайская аномалии, вероятно, имеют общий глубинный корень.

Но сейчас наша задача - вертикальная конфигурация ограничения высокоскоростного Сибирского кратона, определяющая характер его взаимодействия с южными низкоскоростными и более пластичными областями. Модели MOBAL А и Б указывают на одинаковую максимальную толщину кратона в этом сечении, равную 250 км. Для дальнейшей верификации берем модель с лучшим разрешением - модель Б и сравниваем ее с практически совпадающей территориально в окрестности Тункинского рифта моделью $\mathbf{B}$, представляющей собой разрез, полученный методом мультимодальной поверхностно-волновой томографии. В поверхностно-волновой томографии, как отмечалось в разделе 2.1, не определен поверхностный слой Земли толщиной около 80 км. Однако глубже, согласно цветовой легенде модели $\mathbf{B}$, существует полное совпадение аномалий скорости для области, включающей Сибирскую платформу, Торскую впадину и подножие Хамар-Дабана. Существенное расхождение моделей Б и В южнее обусловлено все большим удалением линий разрезов друг от друга. Не противоречит томографии Б и модель Г, рассчитанная до глубины 80 км методом продольной приемной функции и представленная в абсолютных скоростях.

Сопоставление результатов моделирования, выполненных с применением различных подходов (A и Б), а также независимыми методами по независимым данным (Б, В и Г), позволяет однозначно определить позицию южного контакта Сибирского кратона с Центрально-Азиатским складчатым поясом и вертикальную конфигурацию кратона на разрезе MOBAL_2003 и в близко прилегающих районах. Южная граница прочного Сибирского кратона соответствует окраине Сибирской платформы. Предельная глубина подошвы кратона вблизи его южной границы не превышает 250 км. До глубины 120 км контактная поверхность кратона с южными структурами является практически отвесной, воз- можно, в небольшой степени вдавленной в северном направлении. Нижняя часть кратона в этом сечении представляет собой мощный выступ, который почти горизонтально уходит к югу, пододвигаясь под Тункинский рифт и достигая подножия Хамар-Дабана. Такой выступ можно сравнить с ковшом бульдозера. По-видимому, при юго-восточном движении Сибирского кратона, о чем свидетельствуют данные GPS-геодезии [San'kov et al., 2011]), его южный глубинный выступ производит аналогичное бульдозеру воздействие на вышерасположенную менее плотную, чем кратон, толщу среды, вынуждая ее постепенно оседать в месте контакта, в то время как совсем рядом, на юге, растут (выдавливаются не без участия удаленных южных сил) горы. Взаимодействие контактирующих структур осложняется косой горизонтальной компонентой движения, установленной по данным сейсмологии и тектонофизики [Mel'nikova, Radziminovich, 2007; San'kov et al., 2011].

Малопроницаемый кратон препятствует свободной конвекции, под ним накапливаются флюиды и избыточное тепло, о чем можно судить по интенсивной отрицательной аномалии скоростей. Их отток и поднятие к поверхности Земли возможны в зоне относительно подвижного контакта кратона с более молодыми южными структурами. Видимо, во многом благодаря этому обстоятельству, в верхних 50-150 км, как свидетельствуют выявленные томографией низкие скорости сейсмических волн, в непосредственной близости к Сибирскому кратону создаются условия для плавления пород.

\section{5. ХАРАКТЕРИСТИКА ЮГО-ВОСТОЧНОЙ ОКРАИНЫ СИБИРСКОГО КРАТОНА}

Благодаря сравнительно небольшому расстоянию между сейсмостанциями международного телесейсмического трансекта PASSCAL_1992 г., проходящего через юго-восточную окраину Сибирского кратона, Южнобайкальскую впадину, Хэнтей и Гоби-Алтай, по невязкам времен пробега $P$-волн получены относительно детальные модели до глубины 250-700 км (рис. 6). Однако особенности подготовки данных и параметризации моделей сказались таким образом, что толщина высокоскоростной аномалии, ассоциируемая с максимальной толщиной кратона под южной окраиной Сибирской платформы, в полученных моделях не совпадает, варьируясь в пределах 150-250 км [Burkholder et al., 1995; Mordvinova et al., 2000; Tiberi et al., 2003; Zorin et al., 2003; Zhao et al., 2006]. Существенно различается и конфигурация наиболее интенсивной низкоскоростной аномалии под Байкальским рифтом. Тем не менее все, кроме Д. Жао с соавторами 


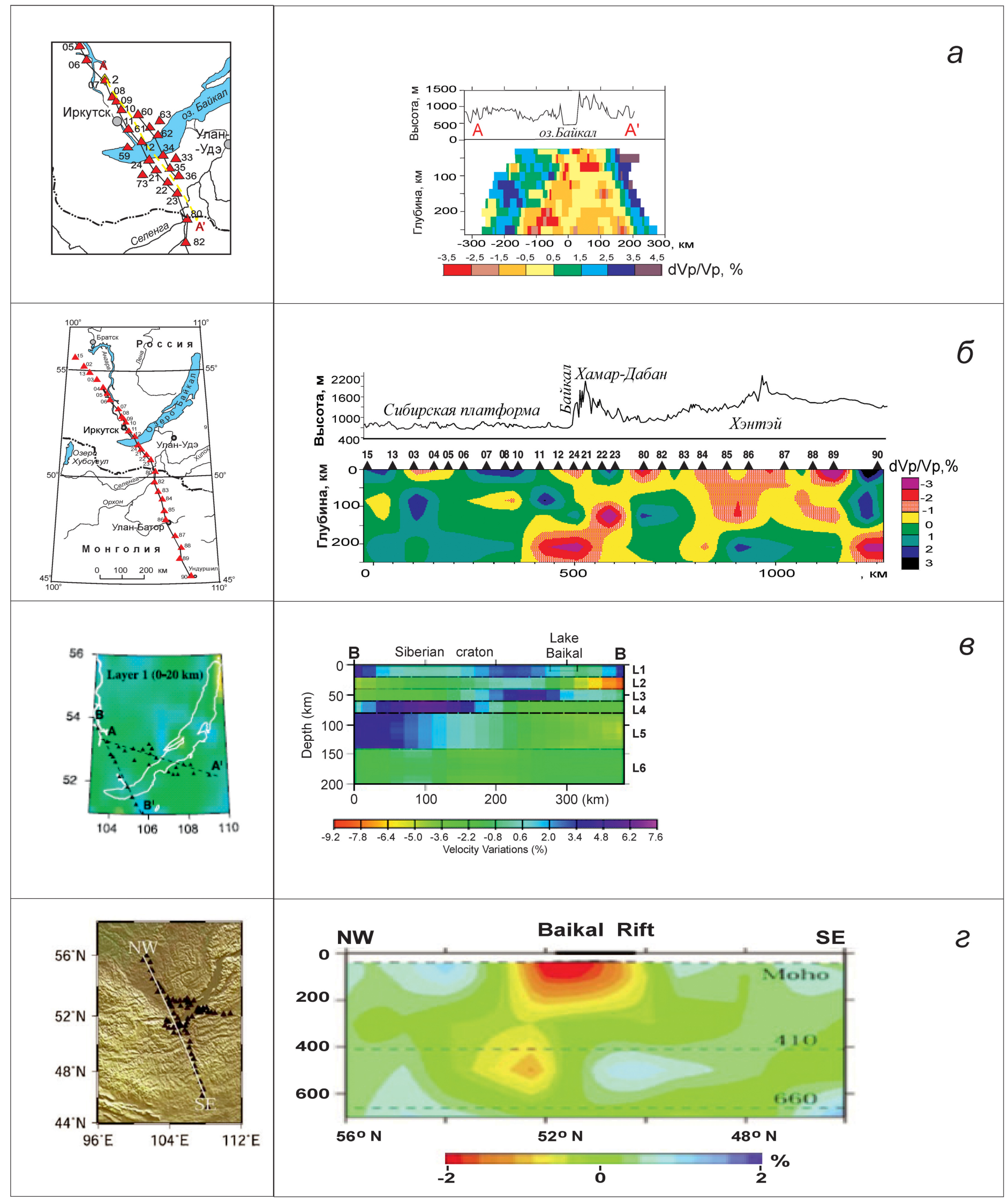

Рис. 6. Сравнение результатов P-томографии по данным наблюдений международного проекта PASSCAL 19911992: a - [Burkholder et al., 1995]; б - [Mordvinova et al., 2000]; в - [Tiberi et al., 2003]; z - [Zhao et al., 2006].

Fig. 6. Comparison of P-tomography results of PASSCAL 1991-1992 international project. Data sources: a - [Burkholder et al., 1995]; б - [Mordvinova et al., 2000]; в - [Tiberi et al., 2003]; ¿ - [Zhao et al., 2006]. 

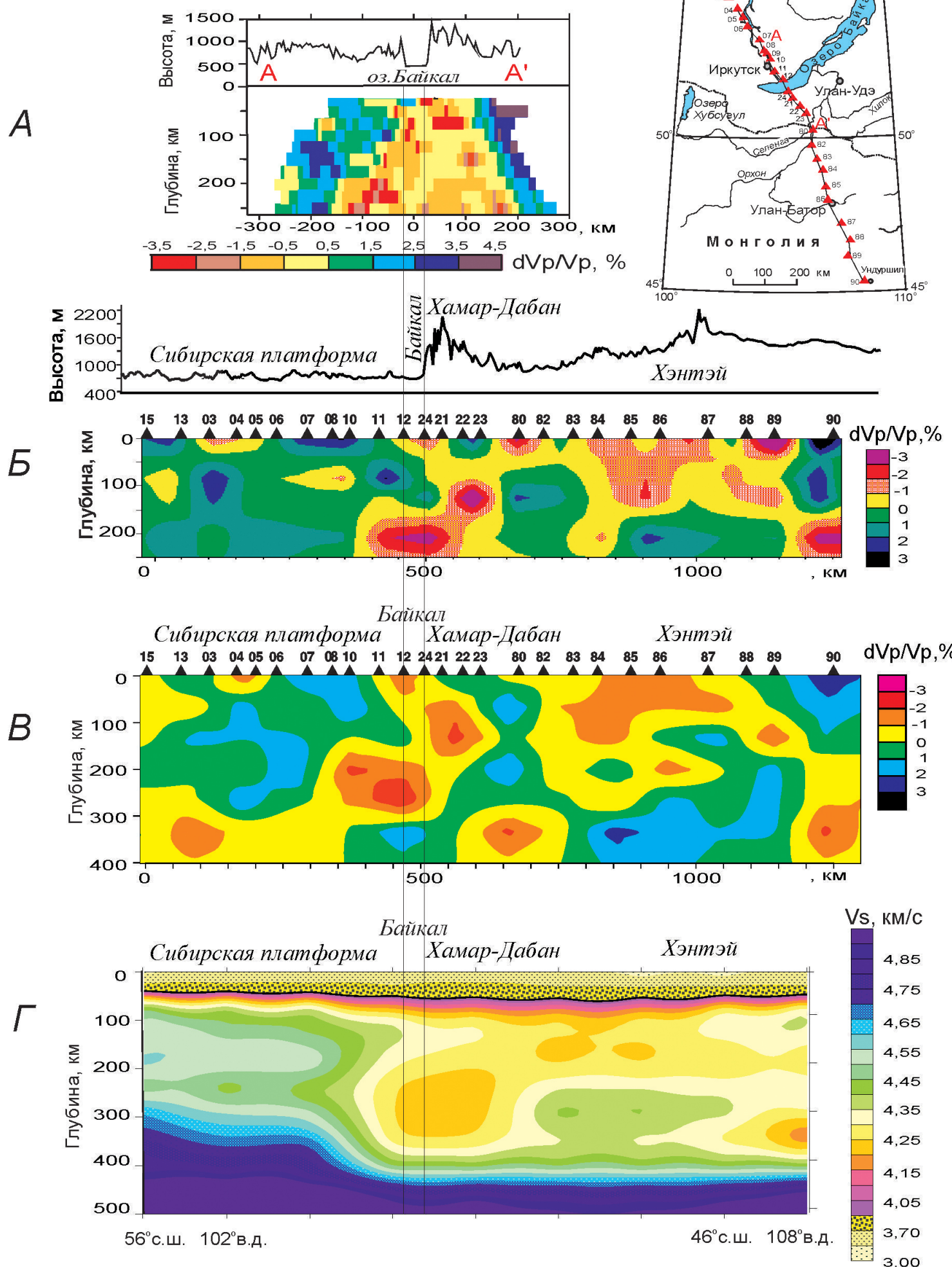

Рис. 7. Сравнение результатов томографии, выполненной различными методами по профилю PASSCAL_1992.

$A$ - P-томография по Байкальскому участку профиля [Burkholder et al., 1995]; 5 - P-томография до глубины 250 км [Mordvinova et al., 2000]; $B$ - P-томография до глубины 400 км; $\Gamma$ - поверхностно-волновая томография [Yanovskaya, Kozhevnikov, 2003; Kozhevnikov, Yanovskaya, 2005].

Fig. 7. Comparison of tomography results obtained for PASSCAL_1992 profile by different methods.

$A$ - P-tomography along the Baikal segment of the profile [Burkholder et al., 1995]; 5 - P-tomography to a depth of $250 \mathrm{~km}$ [Mordvinova et al., 2000]; B - P-tomography to a depth of $400 \mathrm{~km}$; $\Gamma$ - surface-wave tomography [Yanovskaya, Kozhevnikov, 2003; Kozhevnikov, Yanovskaya, 2005]. 


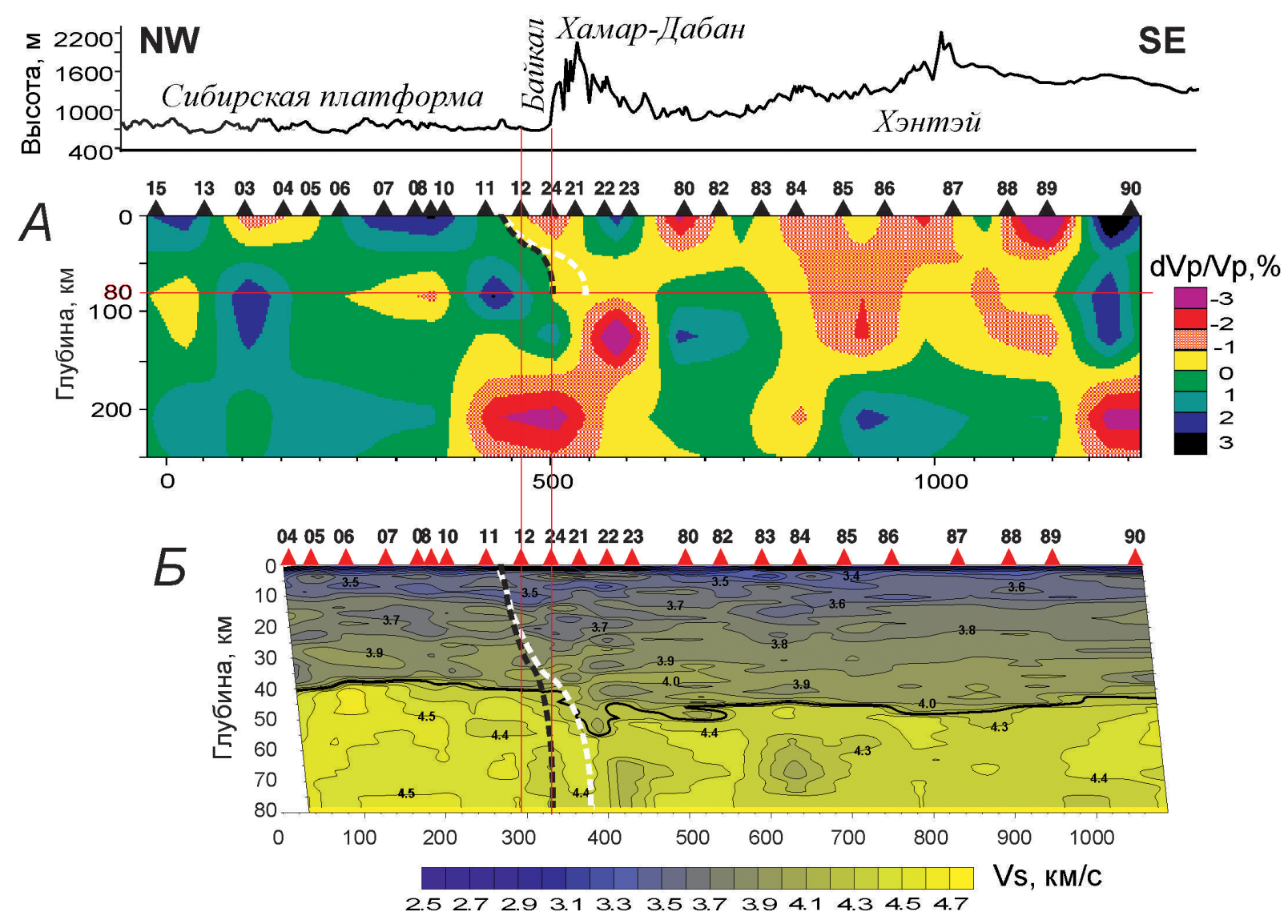

Рис. 8. Определение глубинной границы Сибирского кратона различными методами. $A$ - граница кратона на $P$ томографии (черный пунктир); $Б$ - граница кратона на $V_{S}$-разрезе по данным приемных функций (белый пунктир).

Fig. 8. Determination of the Siberian craton deep border by two methods. A - the dashed black line shows the craton border in P-tomography; $\mathrm{B}$ - the dashed white line is the craton border in the VS-section according to P receiver function data.

[Zhao et al., 2006] (рис. 6, 2), едины в одном - отрицательная аномалия, свидетельствующая об активности мантии, асимметрична относительно рифта, а ее верхняя коромантийная часть находится не под Байкальской впадиной, а сдвинута относительно рифта к юго-востоку. На глубине более 100 км интенсивность аномалии начинает возрастать в северо-западном направлении, достигая максимума в интервале глубин 150-300 км под южной частью Байкальской впадины.

Наиболее информативен томографический образ (рис. 6, б), выявленный инверсией невязок времен пробега вдоль профиля PASSCAL по программе, разработанной А.В. Треусовым [Mordvinova et al., 2000]. Но поскольку инверсии невязок времен пробега до глубины 250 км явно недостаточно, чтобы оценить толщину кратона на данном сечении, по тем же центрированным невязкам, согласно методике, суть которой изложена в разделе 2.2, выполнена инверсия до глубины 400 км и осуществлена верификация моделей (рис. 7). Сверка проведена тщательно, в едином масштабе, без смещения структур относительно друг друга на разных моделях.

Расчет Р-томографии до глубины 400 км (рис. 7, Б) позволил по невязкам времен пробега выявить нижнюю кромку высокоскоростной аномалии, ассоциируемой с юго-восточной окраиной Сибирского кратона, подошва которого в этом сечении достигает 260 км. Несколько меньшая глубина подкоровой высокоскоростной аномалии, характеризующей кратон, определяется по поверхностным волнам (рис. 7, B). Рисунок 7 демонстрирует большое сходство томографий, выполненных различными методами. Если бы результат Г был дан не в абсолютных скоростях, а в общепринятых в томографии процентах, соответствие было бы еще более явным. Таким образом, все четыре модели на рисунке 7 едины в определении конфигурации верхней части контакта высокоскоростного кратона со смежной юго-восточной низкоскоростной областью.

На рисунке 8 проводится сравнение Р-томографической модели этой области (A) с более детальной моделью до глубины 80 км, построенной методом продольной приемной функции (Б). Для удоб- 
ства и большей точности сравнения верхняя часть контактной области модели А выделена черным пунктиром. Пунктир в соответствующем масштабе перенесен на модель Б. S-скоростная модель Б намного детальнее томографической модели А и потому является менее однородной. Тем не менее явно отличаются области пониженной скорости от повышенной (разделены белым пунктиром). В земной коре разделяющие границы, определенные разными методами, совпадают друг с другом. В подкоровой мантии максимальное расхождение между ними примерно 40 км, оно не меняет сути результатов исследования (рис. 8).

На основании комплекса представленных моделей можно сделать заключение о форме юго-восточного краевого выступа Сибирского кратона: на контакте Сибирской платформы с Байкальской складчатой областью кратон принимает форму клина, который под углом около $45^{\circ}$ уходит от поверхности под озеро Байкал и на глубине 100 км полностью выклинивается юго-восточнее озера. Этот клин нависает в форме козырька, выступая километров на 200 к юго-востоку по отношению к основной заглубленной структуре кратона и образуя ловушку для поднимающихся теплопотоков и флюидов. О их повышенной концентрации под наклонным тонким краем Сибирского кратона свидетельствует наиболее интенсивная низкоскоростная аномалия (рис. 8).

Тонкий наклонный юго-восточный край Сибирского кратона и максимально флюидизированная под ним астеносфера, по-видимому, являются существенными составляющими сложного механизма формирования Байкальской впадины и поднятия массива Хамар-Дабан. Понятно, что один профиль PASSCAL_1992 (Братск-Листвянка-Улан-Батор), проходящий через южное окончание озера Байкал, не позволяет судить определенно о геодинамике всего Байкальского рифта. Но, как отмечается во многих работах, например в [Zorin et al., 2003; Mazukabzov et al., 2010], параллельное расположение основных тектонических структур в Забайкалье позволяет в какой-то степени предполагать подобие глубинного строения для значительной части Байкальской впадины и Забайкалья. В таком случае на основании выверенных данных о глубинном строении по профилю PASSCAL_1992 есть возможность уточнить некоторые геологические и геодинамические решения.

\section{6. ЗАКЛЮЧЕНИЕ}

На трансектах международных наблюдений PASSCAL_1991-1992 и MOBAL_2003 записаны ценные сейсмические данные, потенциал которых еще не исчерпан. Полученные по материалам наблюдений широкомасштабные томографические и более детальные модели, рассчитанные методом продольной приемной функции, еще не осмыслены в полной мере. Проведенное исследование в основном коснулось геометрии зоны контакта древнего Сибирского кратона со смежными структурами Центрально-Азиатского подвижного пояса. Большое внимание уделено верификации моделей, поскольку нужно быть убежденным в их надежности, чтобы переходить к серьезной интерпретации. При ближайшем рассмотрении ранее построенных и вновь полученных моделей можно сделать вывод о важном влиянии конфигурации глубинных форм кратона на существующую тектоническую обстановку и геодинамическую историю. Моделирование убедительно показало, что разница в глубинных контактах Сибирского кратона на южной и юго-восточной стороне, кстати, не так сильно удаленных друг от друга, неслучайна. Она объяснима окружающей тектонической обстановкой и, в свою очередь, объясняет ее. Выявлены слабые места Сибирского кратона - верхний «козырек» на юго-востоке и глубинный выступ на юге кратона; их век может быть более коротким, чем у монолитной массы кратона, но вклад в тектонику - достаточно значительным.

\section{7. БЛАГОДАРНОСТИ}

Работа выполнена на материалах международных телесейсмических наблюдений PASSCAL_1992 и MOBAL_2003. Мы обязаны осуществлением этих масштабных проектов людям, которых уже нет с нами, - Р. Майеру, Н.А. Логачеву, Ю.А. Зорину. Мы также выражаем искреннюю признательность иностранным коллегам - С. Гао, Ж. Девершеру, А. Дешам, Т. Дугарме, М. Улзийбату, Т. Баасанбату и многим другим.

Исследования поддержаны грантами инициативного проекта РФФИ № 12-05-01024 и экспедиционных проектов РФФИ 14-05-10028 и 15-0510085.

\section{8. ЛИТЕРАTУРА / REFERENCES}

Aki K., Christofferson A., Husebye E.S., 1977. Determination of three-dimensional seismic structure of the lithosphere. Journal of Geophysical Research 82 (2), 277-296. http://dx.doi.org/10.1029/JB082i002p00277. 
Ammon C.J., Randall G.E., Zandt G., 1990. On the nonuniqueness of receiver function inversion. Journal of Geophysical Research 95 (B10), 15303-15318. http://dx.doi.org/10.1029/JB095iB10p15303.

Barruol G., Deschamps A., Déverchère J., Mordvinova V., Ulziibat M., Perrot J., Artemiev A., Dugarmaa T., Bokelmann G., 2008. Upper mantle flow beneath and around the Hangay dome, Central Mongolia. Earth and Planetary Science Letters 274 (1), 221-233. http://dx.doi.org/10.1016/j.epsl.2008.07.027.

Berkhout A.J., 1977. Least-square inverse filtering and wavelet deconvolution. Geophysics 42 (7), 1369-1383. http:// dx.doi.org/10.1190/1.1440798.

Bertrand E., Deschamps A., 2000. Lithospheric structure of the southern French Alps inferred from broadband analysis. Physics of the Earth and Planetary Interiors 122 (1-2), 79-102. http://dx.doi.org/10.1016/S0031-9201(00) 00188-6.

Burkholder P.D., Meyer R.P., Delitsin L.L., Davis P.M., Zorin Yu.A., 1995. A teleseismic tomography image of the upper mantle beneath the southern Baikal rift zone. In: Proceeding to IUGG XXI General Assembly. Boulder, p. 400.

Egorkin A.V., Pavlenkova N.I., Romanyuk T.V., Solodilov L.N., 1996. Upper-mantle structure along the Baikal-Yamal "Rift" profile, obtained using peaceful nuclear bursts. Geologiya i Geofizika (Russian Geology and Geophysics) 37 (9), 6676 (in Russian) [Егоркин А.В., Павленкова Н.И., Романюк Т.В., Солодилов Л.Н. Структура верхней мантии по профилю Байкал-Ямал “Рифт”, полученная с применением мирных ядерных взрывов // Геология и геофизика. 1996. Т. 37. № 9. С. 66-76].

Emmerson B., Jackson J., McKenzie D., Priestley K., 2006. Seismicity, structure and rheology of the lithosphere in the lake Baikal region. Geophysical Journal International 167 (3), 1233-1272. http://dx.doi.org/10.1111/j.1365-246X. 2006.03075.x.

Gao S., Liu K., Chen C., 2004. Significant crustal thinning beneath the Baikal rift zone: New constraints from receiver function analysis. Geophysical Research Letters 31 (20), L20610. http://dx.doi.org/10.1029/2004GL020813.

Gao S.S., Davis P.M., Liu H., Slack P.D., Zorin Yu.A., Mordvinova V.V., Kozhevnikov V.M., Meyer R.P., 1994. Seismic anisotropy and mantle flow beneath the Baikal rift zone. Nature 371 (6493), 149-151. http://dx.doi.org/10.1038/ 371149a0.

Kennett B.L.N., 1991. IASPEI91 Seismological Tables. Australian National University, Canberra, 167 p.

Kind R., Kosarev G.L., Petersen N.V., 1995. Receiver functions at the stations of the German Regional Seismic Network (GRSN). Geophysical Journal International 121 (1), 191-202. http://dx.doi.org/10.1111/j.1365-246X.1995.tb035 20.x.

Kosarev G.L., Petersen, N.V., Vinnik, L.P., Roecker S.W., 1993. Receiver functions for the Tien Shan analog broadband network: Contrasts in the evolution of structures across the Talass-Fergana fault. Journal of Geophysical Research 98 (B3), 4437-4448. http://dx.doi.org/10.1029/92JB02651.

Kozhevnikov V.M., Yanovskaya T.B., 2005. S-wave velocities distribution in the lithosphere of the Asian continent according to surface Rayleigh waves data. In: K.G. Levi, S.I. Sherman (Eds.), Actual problems of modern geodynamics of Central Asia. Publishing House of the Siberian Branch of the Russian Academy of sciences, Novosibirsk, p. 46-64 (in Russian) [Кожевников В.М., Яновская Т.Б. Распределение скоростей волн S в литосфере Азиатского континента по данным поверхностных волн Рэлея // Актуальные вопросы современной геодинамики Центральной Азии / Ред. К.Г. Леви, С.И. Шерман. Новосибирск: Изд-во СО РАН, 2005. С. 46-64].

Lobkovsky L.I., 1988. Geodynamics of Spreading and Subduction Zones and a Two-Layered Plate Tectonics. Nauka, Moscow, 251 p. (in Russian) [Лобковский Л.И. Геодинамика зон спрединга, субдукции и двухъярусная тектоника плит. М.: Наука, 1988. 251 с.].

Mazukabzov A.M., Donskaya T.V., Gladkochub D.P., Paderin I.P., 2010. The Late Paleozoic geodynamics of the West Transbaikalian segment of the Central Asian fold belt. Russian Geology and Geophysics 51 (5), 482-491. http://dx.doi.org/10.1016/j.rgg.2010.04.008.

Mel'nikova V.I., Radziminovich N.A., 2007. Parameters of seismotectonic deformations of the Earth's crust in the Baikal Rift Zone based on seismological data. Doklady Earth Sciences 416 (1), 1137-1139. http://dx.doi.org/10.1134/ S1028334X07070355.

Mordvinova V.V., Artemyev A.A., 2010. The three-dimensional shear velocity structure of lithosphere in the southern Baikal rift system and its surroundings. Russian Geology and Geophysics 51 (6), 694-707. http://dx.doi.org/ 10.1016/j.rgg.2010.05.010

Mordvinova V.V., Deschamps A., Dugarmaa T., Déverchère J., Ulziibat M., Sankov V.A., Artem'ev A.A., Perrot J., 2007. Velocity structure of the lithosphere on the 2003 Mongolian-Baikal transect from SV waves. Izvestiya, Physics of the Solid Earth 43 (2), 119-129. http://dx.doi.org/10.1134/S1069351307020036.

Mordvinova V.V., Treussov A.V., Turutanov E.K., 2015. Nature of the mantle plume under Hangai (Mongolia) based on seismic and gravimetric data. Doklady Earth Sciences 460 (1), 92-95. http://dx.doi.org/10.1134/S1028334X15 010201.

Mordvinova V.V., Vinnik L.P., Kosarev G.L., Oreshin S.I., Treusov A.V., 2000. Teleseismic tomography of the Baikal rift lithosphere. Doklady Earth Sciences 372 (4), 716-720. 
Pavlenkova G.A., 2012. Upper mantle structure along super-long profile METEORITE (Siberian Craton) carried out with peace nuclear explosion. Geofizicheskiye issledovaniya (Geophysical Researches) 13 (4), 5-18 (in Russian) [Павленкова Г.А. Строение верхней мантии по сверхдлинному профилю МЕТЕОРИТ (Сибирский кратон), отработанному с мирными ядерными взрывами // Геофизические исследования. 2012. Т. 13. № 4. С. 5-18].

Pavlenkova G.A., Priestley K., Cipar J., 2002. 2D model of the crust and uppermost mantle along rift profile, Siberian craton. Tectonophysics 355 (1-4), 171-186. http://dx.doi.org/10.1016/S0040-1951(02)00140-3.

Puzyrev N.N. (Ed.), 1981. Interior of Baikal from Seismic Data. Nauka, Novosibirsk, 173 p. (in Russian) [Недра Байкала по сейсмическим данным / Ред. Н.Н. Пузырев. Новосибирск: Наука, 1981. 173 с.].

Puzyrev N.N. (Ed.), 1993. Detailed Seismic Studies of the Lithosphere Using P and S waves. Nauka, Novosibirsk, 199 p. (in Russian) [Детальные сейсмические исследования литосферы на P- и S-волнах / Ред. Н.Н. Пузырев. Новосибирск: Наука, 1993. 199 с.].

Puzyrev N.N., Mandelbaum M.M., Krylov S.V., Mishenkin B.P., Krupskaya G.V., Petrik G.V., 1974. Deep structure of the Baikal rift from the explosive seismology data. Geologiya i Geofizika (Russian Geology and Geophysics) (5), 155-167 (in Russian) [Пузырев Н.Н., Мандельбаум М.М., Крылов С.В., Мишенькин Б.П., Крупская Г.В., Петрик Г.В. Глубинное строение Байкальского рифта по данным взрывной сейсмологии // Геология и геофизика. 1974. № 5. С. 155-167].

Ritzwoller M.H., Levshin A.L., 1998. Eurasian surface wave tomography: Group velocities. Journal of Geophysical Research 103 (B3), 4839-4878. http://dx.doi.org/10.1029/97JB02622.

San'kov V.A., Lukhnev A.V., Parfeevets A.V., Miroshnichenko A.I., Ashurkov S.V., 2011. Coupling of the crustal and upper mantle deformations in the Mongolia-Siberian Mobile Area. Doklady Earth Sciences 436 (1), 159-164. http://dx.doi.org/10.1134/S1028334X11010302.

Scholz C.A., Klitgord K.D., Hutchinson D.H., ten Brink U.S., Zonenshain L.P., Golmschtok A.Y., Moore T.C., 1993. Results of 1992 seismic reflection experiment in Lake Baikal. Eos, Transactions American Geophysical Union 74 (41), 465470. http://dx.doi.org/10.1029/93E000546.

Sklyarov E.V. (Ed.), 2006. Precambrian Evolution of Southern Part of the Siberian Craton. Publishing House of the Siberian Branch of the Russian Academy of sciences, Novosibirsk, 367 p. (in Russian) [Эволюция южной части Сибирского кратона в докембрии / Ред. Е.В. Скляров. Новосибирск: Изд-во СО РАН, 2006. 367 с.].

Stammler K., 1993. SeismicHandler - programmable multichannel data handler for interactive and automating processing of seismological analyses. Computers \& Geosciences 19 (2), 135-140. http://dx.doi.org/10.1016/00983004(93)90110-Q.

Suvorov V.D., Mel'nik E.A., Mishen'kina Z.R., Pavlov E.V., Kochnev V.A., 2013. Seismic inhomogeneities in the upper mantle beneath the Siberian craton (Meteorite profile). Russian Geology and Geophysics 54 (9), 1108-1120. http://dx.doi.org/10.1016/j.rgg.2013.07.023.

Suvorov V.D., Mishen'kina Z.R., Melnik E.A., 2010. Upper mantle roots of Siberian craton basement structures along the Rift DSS profile. Russian Geology and Geophysics 51 (8), 885-897. http://dx.doi.org/10.1016/j.rgg.2010.07.004.

Suvorov V.D., Mishenkina Z.M., Petrick G.V., Sheludko I.F., Seleznev V.S., Solovyov V.M., 2002. Structure of the crust in the Baikal rift zone and adjacent areas from Deep Seismic Sounding data. Tectonophysics 351 (1-2), 61-74. http://dx.doi.org/10.1016/S0040-1951(02)00125-7.

Ten Brink U.S., Taylor M.H., 2002. Crustal structure of central Lake Baikal: Insights into intracontinental rifting. Journal of Geophysical Research 107 (B7), ETG 2-1-ETG 2-15. http://dx.doi.org/10.1029/2001JB000300.

Tiberi C., Diament M., De'verche're J., Petit-Mariani C., Mikhailov V., Tikhotsky S., Achauer U., 2003. Deep structure of the Baikal rift zone revealed by joint inversion of gravity and seismology. Journal of Geophysical Research 108 (B3), 2133. http://dx.doi.org/10.1029/2002JB001880.

Vinnik L.P., 1977. Detection of waves converted from P to SV in the mantle. Physics of the Earth and Planetary Interiors 15 (1), 39-45. http://dx.doi.org/10.1016/0031-9201(77)90008-5.

Yanovskaya T.B., Kozhevnikov V.M., 2003. 3D S-wave velocity pattern in the upper mantle beneath the continent of Asia from Rayleigh wave data. Physics of the Earth and Planetary Interiors 138 (3-4), 263-278. http://dx.doi.org/10.1016/S0031-9201(03)00154-7.

Zhao D., Lei J., Inoue T., Yamada A., Gao S.S., 2006. Deep structure and origin of the Baikal rift zone. Earth and Planetary Science Letters 243 (3), 681-691. http://dx.doi.org/10.1016/j.epsl.2006.01.033.

Zorin Y.A., Balk T.V., Novoselova M.R., Turutanov E.Kh., 1988. Lithospheric thickness beneath the Mongol-Siberian highlands and adjacent regions. Fizika Zemli (7), 33-42 (in Russian) [Зорин Ю.А., Балк Т.В., Новоселова М.P., Турутанов E.X. Толщина литосферы под Монголо-Сибирской горной страной и сопредельными регионами // Физика Земли. 1988. № 7. С. 33-42].

Zorin Y.A., Mordvinova V.V., Turutanov E.K., Belichenko V.G., Artemyev A.A., Kosarev G.L., Gao S.S., 2002. Low seismic velocity layers in the Earth's crust beneath Eastern Siberia (Russia) and Central Mongolia: receiver function data and their possible geological implication. Tectonophysics 359 (3-4), 307-327. http://dx.doi.org/10.1016/S00401951(02)00531-0. 
Zorin Yu.A., Turutanov E.Kh., Mordvinova V.V., Kozhevnikov V.M., Yanovskaya T.B., Treussov A.V., 2003. The Baikal rift zone: the effect of mantle plumes on older structure. Tectonophysics 371 (1-4), 153-173. http://dx.doi.org/ 10.1016/S0040-1951(03)00214-2.

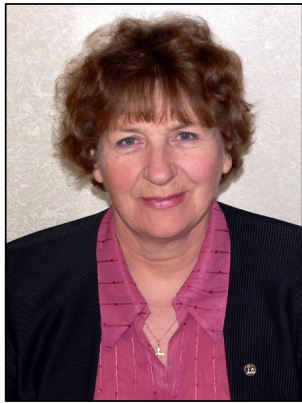

Мордвинова Валентина Владимировна, докт. геол.-мин. наук, в.н.с.

Институт земной коры СО РАН

664033, Иркутск, ул. Лермонтова, 128, Россия

Тел.: (3952)422761; $ه$ e-mail: mordv@crust.irk.ru

Mordvinova, Valentina V., Doctor of Geology and Mineralogy, Lead Researcher Institute of the Earth's Crust, Siberian Branch of RAS

128 Lermontov street, Irkutsk 664033, Russia

Tel.: (3952)422761; $\bowtie$ e-mail: mordv@crust.irk.ru

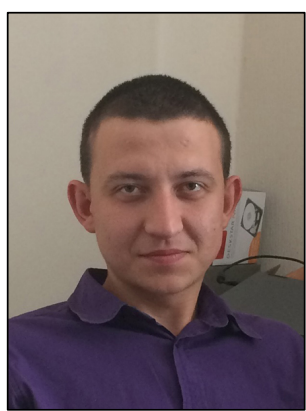

Кобелев Михаил Михайлович, ведущий инженер, аспирант

Байкальский филиал Геофизической службы СО РАН

664033, Иркутск, ул. Лермонтова, 128, Россия

Тел.: (3952)429957; e-mail: kobelevmm@gmail.com

Kobelev, Mikhail M., Engineer, Postgraduate Student

Baikal Division of Geophysical Survey, Siberian Branch of RAS

128 Lermontov street, Irkutsk 664033, Russia

Tel.: (3952)429957; e-mail: kobelevmm@gmail.com

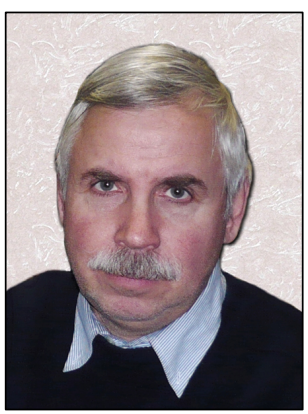

Треусов Александр Владимирович, канд. физ.-мат. наук, в.н.с. Институт физики Земли им. О.Ю. Шмидта РАН

123242, ГСП-5, Москва Д-242, ул. Большая Грузинская, 10, Россия

e-mail: treussov@ifz.ru

Treussov, Aleksandr V., Candidate of Physics and Mathematics, Lead Researcher O.Yu. Schmidt Institute of Physics of the Earth of RAS

10 Bol'shaya Gruzinskaya street, Moscow D-242 123242, GSP-5, Russia

e-mail: treussov@ifz.ru

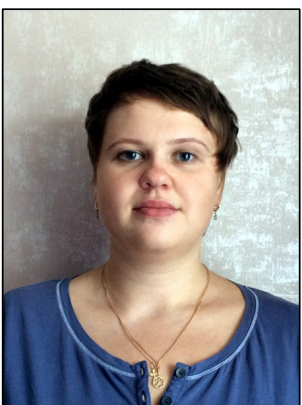

Хритова Мария Анатольевна, ведущий программист

Байкальский филиал Геофизической службы СО РАН

664033, Иркутск, ул. Лермонтова, 128, Россия

Тел.: (3952)511231; e-mail: hritova@crust.irk.ru

Khritova, Maria A., Lead Programmer

Baikal Division of Geophysical Survey, Siberian Branch of RAS

128 Lermontov street, Irkutsk 664033, Russia

Tel.: (3952)511231; e-mail: hritova@crust.irk.ru 


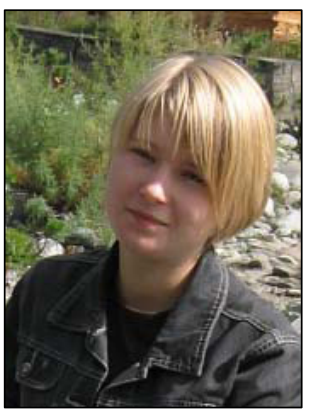

Трынкова Дарья Сергеевна, аспирант

Институт земной коры СО РАН

664033, Иркутск, ул. Лермонтова, 128, Россия

Тел.: (3952)422761; e-mail: trdaria@mail.ru

Trynkova, Daria S., Postgraduate Student

Institute of the Earth's Crust, Siberian Branch of RAS

128 Lermontov street, Irkutsk 664033, Russia

Tel.: (3952)422761; e-mail: trdaria@mail.ru

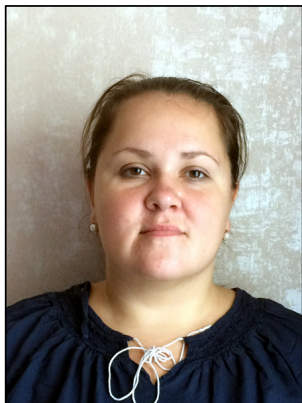

Кобелева Елена Анатольевна, канд. физ.-мат. наук, руководитель ГПН

Байкальский филиал Геофизической службы СО РАН

664033, Иркутск, ул. Лермонтова, 128, Россия

Тел.: (3952)429957; e-mail: ekobeleva@crust.irk.ru

Kobeleva, Elena A., Candidate of Physics and Mathematics, Head of Group of seismological observations Baikal Division of Geophysical Survey, Siberian Branch of RAS

128 Lermontov street, Irkutsk 664033, Russia

Tel.: (3952)429957; e-mail: ekobeleva@crust.irk.ru

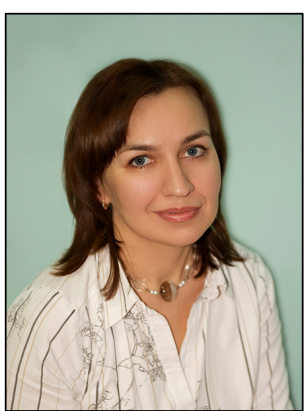

Лухнева Ольга Федоровна, канд. геол.-мин. наук, н.с.

Институт земной коры СО РАН

664033, Иркутск, ул. Лермонтова, 128, Россия

Тел.: (3952)429534; e-mail: olgal@crust.irk.ru

Lukhneva, Olga F., Candidate of Geology and Mineralogy, Researcher Institute of the Earth's Crust, Siberian Branch of RAS

128 Lermontov street, Irkutsk 664033, Russia

Tel.: (3952)429534; e-mail: olgal@crust.irk.ru 